\title{
Influence of meter-scale wind-formed features on the variability of the microwave brightness temperature around Dome $\mathrm{C}$ in Antarctica
}

\author{
G. Picard ${ }^{1,2}$, A. Royer $^{3}$, L. Arnaud ${ }^{1,2}$, and M. Fily ${ }^{1,2}$ \\ ${ }^{1}$ University Grenoble Alpes, LGGE UMR5183, 38041 Grenoble, France \\ ${ }^{2}$ CNRS, LGGE UMR5183, 38041 Grenoble, France \\ ${ }^{3}$ Centre d'Applications et de Recherches en Télédétection (CARTEL), Université de Sherbrooke, \\ 2500 boul. Université, Sherbrooke, Quebec, J1K 2R1, Canada
}

Correspondence to: G. Picard (ghislain.picard@ujf-grenoble.fr)

Received: 26 June 2013 - Published in The Cryosphere Discuss.: 23 July 2013

Revised: 5 March 2014 - Accepted: 3 May 2014 - Published: 24 June 2014

\begin{abstract}
Space-borne passive microwave radiometers are widely used to retrieve information in snowy regions by exploiting the high sensitivity of microwave emission to snow properties. For the Antarctic Plateau, many studies presenting retrieval algorithms or numerical simulations have assumed, explicitly or not, that the subpixel-scale heterogeneity is negligible and that the retrieved properties were representative of whole pixels. In this paper, we investigate the spatial variations of brightness temperature over a range of a few kilometers in the Dome $\mathrm{C}$ area. Using ground-based radiometers towed by a vehicle, we collected brightness temperature at 11,19 and $37 \mathrm{GHz}$ at horizontal and vertical polarizations along transects with meter resolution. The most remarkable observation was a series of regular undulations of the signal with a significant amplitude reaching $10 \mathrm{~K}$ at $37 \mathrm{GHz}$ and a quasi-period of $30-50 \mathrm{~m}$. In contrast, the variability at longer length scales seemed to be weak in the investigated area, and the mean brightness temperature was close to SSM/I and WindSat satellite observations for all the frequencies and polarizations. To establish a link between the snow characteristics and the microwave emission undulations, we collected detailed snow grain size and density profiles at two points where opposite extrema of brightness temperature were observed. Numerical simulations with the DMRT-ML microwave emission model revealed that the difference in density in the upper first meter explained most of the brightness temperature variations. In addition, we found that these variations of density near the surface were linked to snow hardness. Patches of hard snow - probably formed by
\end{abstract}

wind compaction - were clearly visible and covered as much as $39 \%$ of the investigated area. Their brightness temperature was higher than in normal areas. This result implies that the microwave emission measured by satellites over Dome $\mathrm{C}$ is more complex than expected and very likely depends on the year-to-year areal proportion of the two different types of snow.

\section{Introduction}

Space-borne passive microwave radiometers are among the most useful tools to study snow and collect information on the Antarctic climate. They have several advantages over other remote sensing techniques: high sensitivity to snow properties (temperature, grain size, density), subdaily coverage in the polar regions, and independence of cloud conditions and solar illumination. Typical applications for ice sheets aim to retrieve snow temperature (Shuman et al., 1995; Schneider and Steig, 2002; Schneider et al., 2004), snowmelt (e.g., Zwally, 1977; Abdalati and Steffen, 1995; Torinesi et al., 2003), snow accumulation (Vaughan et al., 1999; Arthern et al., 2006), grain size (Brucker et al., 2010; Picard et al., 2012), thermal properties (Koenig et al., 2007; Picard et al., 2009) or surface state (Shuman et al., 1993; Champollion et al., 2013). Passive microwave data are also widely used in assimilation schemes to constrain atmospheric analyses for which the surface emissivity is an issue, particularly over Antarctica (Guedj et al., 2010). These radiometers, however, 
have a coarse spatial resolution, typically $10-60 \mathrm{~km}$ depending on the frequency and the antenna size of the radiometer (Colton and Poe, 1999; Kerr et al., 2010). In Antarctic coastal and mountainous regions, the heterogeneity within the radiometer footprint is significant because of the topography. This limits, for instance, the interpretation of snowmelt events detected by passive microwave data (e.g., van den Broeke et al., 2009). In other regions, and specifically on the flat East Antarctic Plateau, the heterogeneity of the snowpack is less obvious and its impact on microwave observations is unknown. However, all the applications cited above presuppose, explicitly or not, that the snow characteristics are spatially homogeneous within the radiometer footprint. This assumption is also required when emission models are run using snow properties measured in one point and results are compared to satellite data (Macelloni et al., 2006; Brucker et al., 2011). Advanced approaches for dealing with the subpixel heterogeneity, like unmixing (e.g., Painter et al., 2009), have not yet been considered in Antarctica for passive microwave remote sensing as opposed to other continental surfaces (Kerr et al., 2012).

The large-scale spatial variations of brightness temperature in Antarctica are well known (e.g., Schneider and Steig, 2002; Fahnestock et al., 2000). The spatial variations of brightness temperature are generally continuous, except in coastal and mountainous regions. Snow properties retrieved from microwave data, like the accumulation (Vaughan et al., 1999; Arthern et al., 2006) or the grain size profile (Brucker et al., 2011), are also spatially continuous. This suggests that the snowpack from one pixel to a neighbor is generally similar. A particularly homogeneous area was identified on the ice divide near Dome C (Macelloni et al., 2007), which might be suitable for the calibration of passive microwave satellites (Macelloni et al., 2006).

It is, however, evident to most observers in the field that the snow surface is highly variable at the meter and decameter scales even on the plateau (Furukawa et al., 1996). Most of the visible features are formed by the erosion and by selective deposition of snow resulting from wind and turbulence. These wind-formed features include ripples, sastrugi and dunes (Kobayashi and Ishida, 1979). Glazed surfaces (Frezzotti et al., 2002a; Scambos et al., 2012), thermal cracks and irregular patches of hoar on the surface (Gow, 1969; Courville et al., 2007) can also be found at some specific points. These features affect the distribution of snow accumulation and represent one of the challenges in scaling up local surface mass balance measurements to the continent scale (Goodwin, 1990; Magand et al., 2008; Das et al., 2013). Although the size of these features is much smaller than the microwave radiometer footprint, they have an influence on the signal. Microwave observations are indeed dependent on the viewing azimuth angle. This is most pronounced for the third and fourth Stokes vector components (Narvekar et al., 2006, 2010). This is weak but detectable for the conventional horizontal and vertical polarizations. For instance, Long and
Drinkwater (2000) found that the variations of brightness temperature due to the viewing azimuth angle are about $2 \mathrm{~K}$ rms at Dome $\mathrm{C}\left(75^{\circ} \mathrm{S}, 123^{\circ} \mathrm{E}\right)$ and are as large as $5 \mathrm{~K}$ in the Lambert Glacier basin, which is well above the noise level $(<1 \mathrm{~K})$. It is also significant in active remote sensing with altimeters (Remy et al., 2006) and scatterometers (Hyland and Young, 1998; Long and Drinkwater, 2000). In general, the variations are symmetric with respect to the prevailing wind direction (Long and Drinkwater, 2000), which suggests that the wind-formed features visible at the surface or those buried within the snowpack have a significant influence on microwave emission. However, the snow characteristics and wave-matter interactions responsible for the azimuthal dependence are unknown.

At intermediate scales - ranging from the scales accessible to observers in the field to the pixel scale - the spatial variations can be observed with high- and moderate-resolution optical sensors (e.g., Scambos et al., 2007; Nolin et al., 2002), high-resolution radar (Jezek, 1999) or ground penetrating radar. Notable features include crevasse fields, megadunes (Fahnestock et al., 2000; Frezzotti et al., 2002b), hidden dunes (Anschütz et al., 2006) and emerging features of subglacial lakes. These well-known features could, in principle, be masked out in the studies for which the homogeneity of the pixels is critical. This is not the case for the wind-formed features that cover the whole continent and whose areal proportion within a pixel might vary over time (Lacroix et al., 2009).

If the sub-pixel heterogeneity had a significant influence on the microwave signal, it would call into question the representativeness of the parameters retrieved from passive microwave observations in many studies and of the robustness of modeling validation work. Quantifying this influence is therefore important to better understand the relationship between the microwave observations and the snow properties, to improve satellite calibration experiments or retrieval algorithms and to combine observations from sensors having different spatial resolutions (e.g., passive microwave radiometers and altimeters).

The objective of this study is to analyze the variability of brightness temperature at subpixel scale around Dome C. To collect the data, we used three ground-based radiometers with a footprint on the order of $1 \mathrm{~m}$ operating at a frequency of 11,19 and $37 \mathrm{GHz}$. The radiometers were towed by a vehicle, thus providing measurements over a few kilometers with a resolution of a few meters. In addition, we collected detailed vertical profiles of snow properties at two distinct locations in order to run a microwave emission model and determine the properties responsible for the observed variations between the points.

The following sections first describe the ground-based radiometric data and the snow in situ data collected during the austral summer field campaign in 2012. Then we present the results at different spatial scales and investigate the possible causes of the observed variations. 


\section{Data and study area}

A series of ground-based microwave radiometric measurements were acquired in January 2012 at Dome C in conjunction with snow property measurements taken in drilled holes up to $8-10 \mathrm{~m}$ deep. Temperature profiles recorded hourly near the station were also available.

\subsection{Radiometric measurements}

Three dual-polarimetric radiometers $\left(\right.$ Radiometrics $\left.^{(}\right)$at 10.67 (hereafter referred to as 11), 19 and $37 \mathrm{GHz}$ were deployed on a sledge and used between 25 and 31 January to acquire brightness temperature data in an area east of the Concordia Station near Dome C (Fig. 1). Two types of measurements were acquired: (1) continuous measurements along a series of kilometer-long transects to characterize the spatial variations of brightness temperature and (2) angular diagrams at two specific locations selected for their contrasting conditions.

For the transect measurements, the sledge was towed by a vehicle at moderate speed between 3 and $5 \mathrm{~km} \mathrm{~h}^{-1}$. The radiometers were continuously operating and provided measurements with an integration time of $6 \mathrm{~s}$. With an average speed of $4 \mathrm{~km} \mathrm{~h}^{-1}$, it corresponded to an along-track horizontal resolution of about $7 \mathrm{~m}$. The cross-track resolution depended on the radiometer aperture (about $8^{\circ}$ for $11 \mathrm{GHz}$ and $6^{\circ}$ for 19 and $37 \mathrm{GHz}$ ), radiometer height above ground (about $1.5 \mathrm{~m}$ ) and the radiometer inclination angle with respect to the vertical (referred to as the incidence angle). It was on the order of $60 \mathrm{~cm}$ for an incidence angle of $55^{\circ}$. In addition, two transects (200-300 m long) were acquired at a slower speed $\left(<1 \mathrm{~km} \mathrm{~h}^{-1}\right)$, thus providing measurements at a finer horizontal resolution. To determine the repeatability, the A3-A4 transect (see Fig. 1) was repeated three times for three different days at nearly constant incidence angle. The S4-S5 transect was repeated four times with varying incidence angles the same day. The position of the vehicle was recorded by GPS every second with an estimated precision better than $5 \mathrm{~m}$ (when the vehicle was immobile). The sledge with the radiometers was about $7 \mathrm{~m}$ behind the GPS receiver. On the high-resolution transects, the track of the sledge was exactly the same $(<10 \mathrm{~cm} \mathrm{rms})$ for the successive passes, which was negligible with respect to the GPS localization error.

Static measurements were taken at two locations (called SP1 and SP2; see Fig. 1) where contrasting brightness temperatures were noticed along the transects. The angular diagrams were acquired by recording measurements over at least $3 \mathrm{~min}$ for every angle. Since the radiometer position was fixed, the footprint center at the surface was located at $0.4 \mathrm{~m}$ from the radiometer vertical for incidence angle of $20^{\circ}$ and $2.5 \mathrm{~m}$ for incidence angle of $65^{\circ}$. The volume from which the radiation emanated was larger than that since the pene- tration depth was on the order of $0.75 \mathrm{~m}$ at $37 \mathrm{GHz}$ and $4 \mathrm{~m}$ at $19 \mathrm{GHz}$ (Surdyk, 2002; Picard et al., 2009).

Several experimental issues limited the quality of the data set: microwave radiometers are sensitive instruments that require a stabilized inner temperature at $+40^{\circ} \mathrm{C}$. With air temperature during the measurements around $-37^{\circ} \mathrm{C}$, the stability was challenging. Based on several calibrations with an ambient blackbody, we inferred that absolute accuracy was on the order of $3 \mathrm{~K}$. This value was confirmed by day-to-day variations observed during the repeatability tests and by comparing data acquired on different dates along the same transect (Sect. 2.2). Nevertheless, the stability of the radiometers over daily and shorter terms was much better. For instance, during the static measurements, the variations were not greater than $0.1 \mathrm{~K} \mathrm{rms}$ for at least 3 minutes at all the frequencies and incidence angles.

Another issue is the variation of the inclination of the radiometers during the transect measurements. The inclination was not constant owing to sledge movement (rolling) and relaxation of the radiometer mounting due to vibrations. Based on the incidence angles measured within each radiometer with every brightness temperature acquisition, it was possible to discard the records at angles outside of a specified range (e.g., $50-57^{\circ}$, the precise values are chosen for each graph; see Sect. 3)

In addition, there was a problem with the electronics of the $37 \mathrm{GHz}$ radiometer, and it only recorded every other measurement (i.e., every $12 \mathrm{~s}$ ). This resulted in a degraded alongtrack resolution. The $11 \mathrm{GHz}$ radiometer was available only on the site the last 2 days due to logistical constraints. Despite these issues, the data set showed consistent spatial variations (Sect. 3.1) whose amplitude was much larger than the uncertainties.

For comparison with ground data, observations from the space-borne SSM/I and WindSat radiometers were extracted respectively from the "DMSP SSM/I Daily Polar Gridded Brightness Temperatures" data set (Maslanik and Stroeve, 2012) and from the SDR WindSat product (Gaiser et al., 2004) obtained from Computational Physics, Inc. for the period matching the ground-based measurements. Satellite data were converted into surface brightness temperature by subtracting the upwelling atmospheric brightness temperature and normalizing by the atmospheric transmissivity. These atmospheric parameters were calculated using an atmospheric absorption microwave model (Liebe , 1989). The model was driven by the air temperature and moisture profiles derived from radiosounding acquired at Dome $\mathrm{C}$ (data were obtained from IPEV/PNRA Project Routine Meteorological Observation at Station Concordia (www.climantartide.it)). Note that both the ground-based measurements and the corrected satellite brightness temperatures include the reflected downwelling atmospheric component and are therefore comparable. 


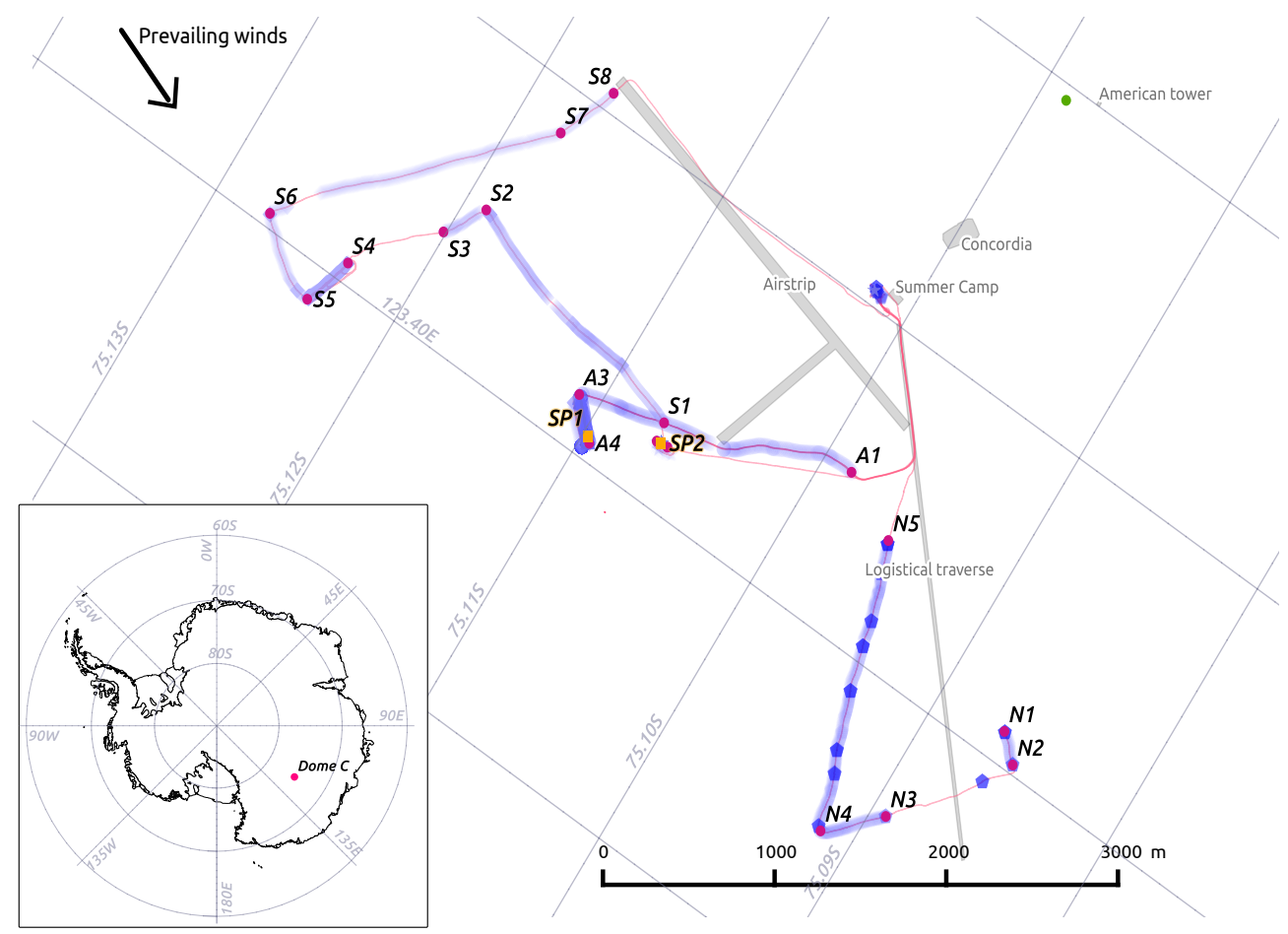

Figure 1. Location of the experiment in January 2012. The semi-transparent blue symbols represent the individual measurements. The letter and number labels identify points along the transects used for reference. SP1 and SP2 are the locations where detailed snow property measurements were collected to run the DMRT-ML microwave emission model. The green point identifies the location of the snow temperature profile.

\subsection{Snow properties}

The SP1 and SP2 locations (Fig. 1) where contrasting brightness temperatures were noticed were located $400 \mathrm{~m}$ apart and differed at first sight by the hardness of the snow: soft (SP1) and very hard (SP2). SP1 also seemed to be about $10-20 \mathrm{~cm}$ lower than the surrounding surface while SP2 was located relatively higher. In order to investigate the causes of the spatial variations of brightness temperature, we measured profiles of snow grain size, density and temperature (Fig. 2) necessary to run a microwave emission model.

The snow grain size was measured down to $8 \mathrm{~m}$ depth using the Profiler Of Snow Specific Surface area Using shortwave infrared reflectance Measurement (POSSSUM, Arnaud et al., 2011). This instrument measures the reflectance (at 1300 and $805 \mathrm{~nm}$ ) of the snow face in drilled holes with a centimeter vertical resolution. The reflectances are converted into specific surface area (SSA) using a complex algorithm (Arnaud et al., 2011) that was validated with independent measurements (Gallet et al., 2009). The accuracy was estimated to $12 \%$. The SSA is equivalent to the optical radius (e.g., Grenfell and Warren, 1999; Arnaud et al., 2011) and can be used to run microwave emission models after adaptation as described in Sect. 2.3.

The density profiles were measured on snow cores sliced every $5 \mathrm{~cm}$ with a miter saw. The height and diameter of each sample were measured with a caliper to deduce the volume assuming a cylindrical shape. The mass was measured with a precision balance. The largest uncertainty came from the diameter measurements and was larger in the upper part of the profile where the snow was less cohesive and some samples were only approximately cylindrical. We estimated that the accuracy was better than $10 \%$ for the cohesive samples in depth and did not exceed $20 \%$ for the less cohesive samples.

The temperature profile was recorded near Concordia Station (Fig. 1) using a string of 40 temperature probes set up in December 2006 from the surface to $20 \mathrm{~m}$ depth (Brucker et al., 2011). Daily measurements at $50 \mathrm{~cm}$ depth are shown in Fig. 3 along with the daily air temperature from the Antarctic Meteorological Research Center (AMRC) and Automatic Weather Station (AWS) program. SSM/I daily brightness temperatures are also shown on a separate $y$ axis. During the fieldwork campaign (shaded gray bar in Fig. 3), the $50 \mathrm{~cm}$ deep snow temperature decreased by $-2.6^{\circ} \mathrm{C}$, the air temperature by $-3.8^{\circ} \mathrm{C}$ and the brightness temperature by $-2.6 \mathrm{~K}$ (at $37 \mathrm{~V}$-pol) or less (for the three other configurations). Hence, the variations of snow temperature and brightness temperature were moderate and smaller than the calibration accuracy of the radiometers. We therefore interpreted our measurements taken on different days assuming constant conditions. 


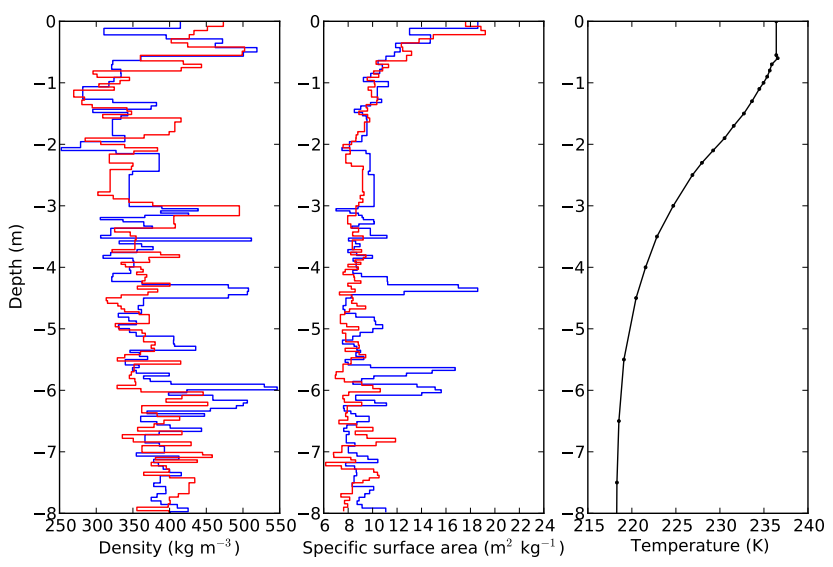

Figure 2. Density and snow-specific surface area profiles at SP1 (blue, soft snow, low brightness temperature) and SP2 (red, hard snow, high brightness temperature). Temperature profile recorded near the station.

The temperature profile was required for modeling the brightness temperature. With an actual snow accumulation of about $8-10 \mathrm{~cm}$ per year at Dome C, the probe installed near the surface in 2006 was at about $50 \mathrm{~cm}$ depth in January 2012. Even though no temperature data were measured above this depth, we assumed that, during the particular period of the fieldwork campaign, the temperature was uniform in the uppermost $50 \mathrm{~cm}$. This was supported by the fact that (1) the air and $50 \mathrm{~cm}$ temperatures were close and (2) were almost constant during the campaign. Since the temperature profile is governed by diffusion processes, strong temperature gradients could hardly have persisted during this period under these conditions. For modeling, we used the temperature profile averaged over the period.

\subsection{DMRT-ML modeling}

The Dense Media Radiative Transfer model - Multi Layer (DMRT-ML) predicts the brightness temperature for snowcovered areas from the physical properties of the snowpack. The model is described in detail in Picard et al. (2013) and is available online (http://lgge.osug.fr/ picard/dmrtml/). Each snow layer is fully described by the temperature, density, the radius of the ice spheres representing the snow, and by the amount of liquid water.

The model was evaluated at Dome C (Brucker et al., 2011, B11 hereafter) using similar inputs as used here considering monodisperse nonsticky ice spheres to represent snow. An important result of B11 is that the grain size derived from the SSA - i.e., the radius of the spheres having the same SSA as the snow, $r=\frac{3}{\operatorname{SSA} \rho_{\text {ice }}}$ where $\rho_{\text {ice }}=917 \mathrm{~kg} \mathrm{~m}^{-3}$ - must be scaled by an empirical factor $\phi$ to obtain modeling results in reasonable agreement with the observations $(2 \mathrm{~K} \mathrm{rms}$ over a $2 \mathrm{yr}$ long time series of daily brightness temperature; see B11 for details). The optimal $\phi$ value was 2.8 in B11.

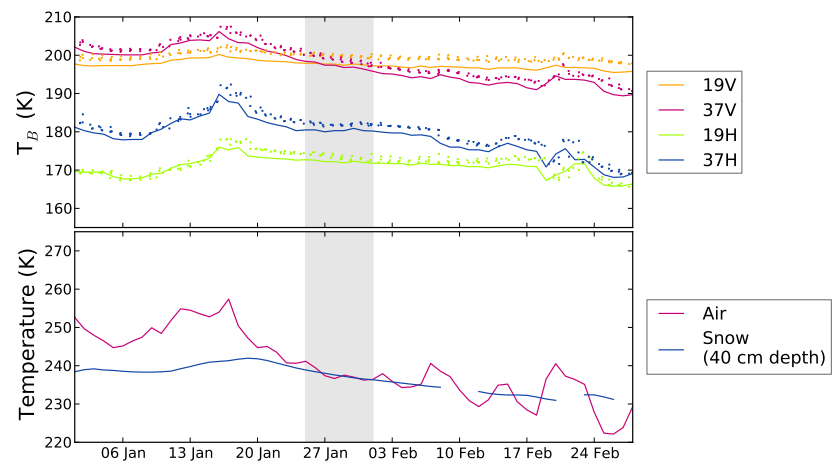

Figure 3. Evolution of SSM/I brightness temperatures at 19 and $37 \mathrm{GHz}$ and vertical and horizontal polarizations in January and February 2012. Air temperature measured by the Antarctic Automatic Weather Station Project (AWS) and snow temperature at $50 \mathrm{~cm}$ depth. The gray bar shows the period of ground-based radiometric measurements.

Roy et al. (2013) and Dupont et al. (2014) have confirmed these results using a similar approach with independent data and in different environments, but they have found slightly higher values of $\phi$. The need to introduce $\phi$ is probably due to the representation of snow microstructure by monodisperse nonsticky spheres as discussed in Roy et al. (2013).

The method applied here follows B11, with several improvements: (1) the $\phi$ factor was optimized with snow measurements and brightness temperature measurements from two different locations (SP1 and SP2) instead of one, and (2) our SSA profiles were $8 \mathrm{~m}$ long instead of $3 \mathrm{~m}$ in B11. An important consequence was that we did not need the optimization of a second parameter to represent the mean grain size below the measured profile as used in B11; (3) the snow layers containing more ice than air per volume (i.e., density was larger than $458 \mathrm{~kg} \mathrm{~m}^{-3}$ ) were represented by air spheres embedded in an ice background instead of ice spheres in an air background. It yielded a better representation of the medium (Dierking et al., 2012; Picard et al., 2013; Dupont et al., 2014) and extended the validity of the DMRT theory towards large density values.

The layer thickness in the simulations was taken from the density measurements, i.e., approximately $5 \mathrm{~cm}$ thick, except where snow was too brittle or at the transitions between the cores where some material was inevitably lost. A total of 193 and 172 layers was used for SP1 and SP2 respectively. The lowest layer in the simulation extended to infinity. Its properties were taken from the lowest available density measurements, at $11.7 \mathrm{~m}$ depth for SP1 and $10.5 \mathrm{~m}$ for SP2. The temperature in each layer was determined by linear interpolation of the measured profiles. The SSA profile measured at a resolution better than $1 \mathrm{~cm}$ was downscaled by averaging in each layer. The mean SSA was then converted into sphere radius $r$ and multiplied by the factor $\phi$. The SSA value at $8 \mathrm{~m}$ depth was used for all the layers below this depth. This 


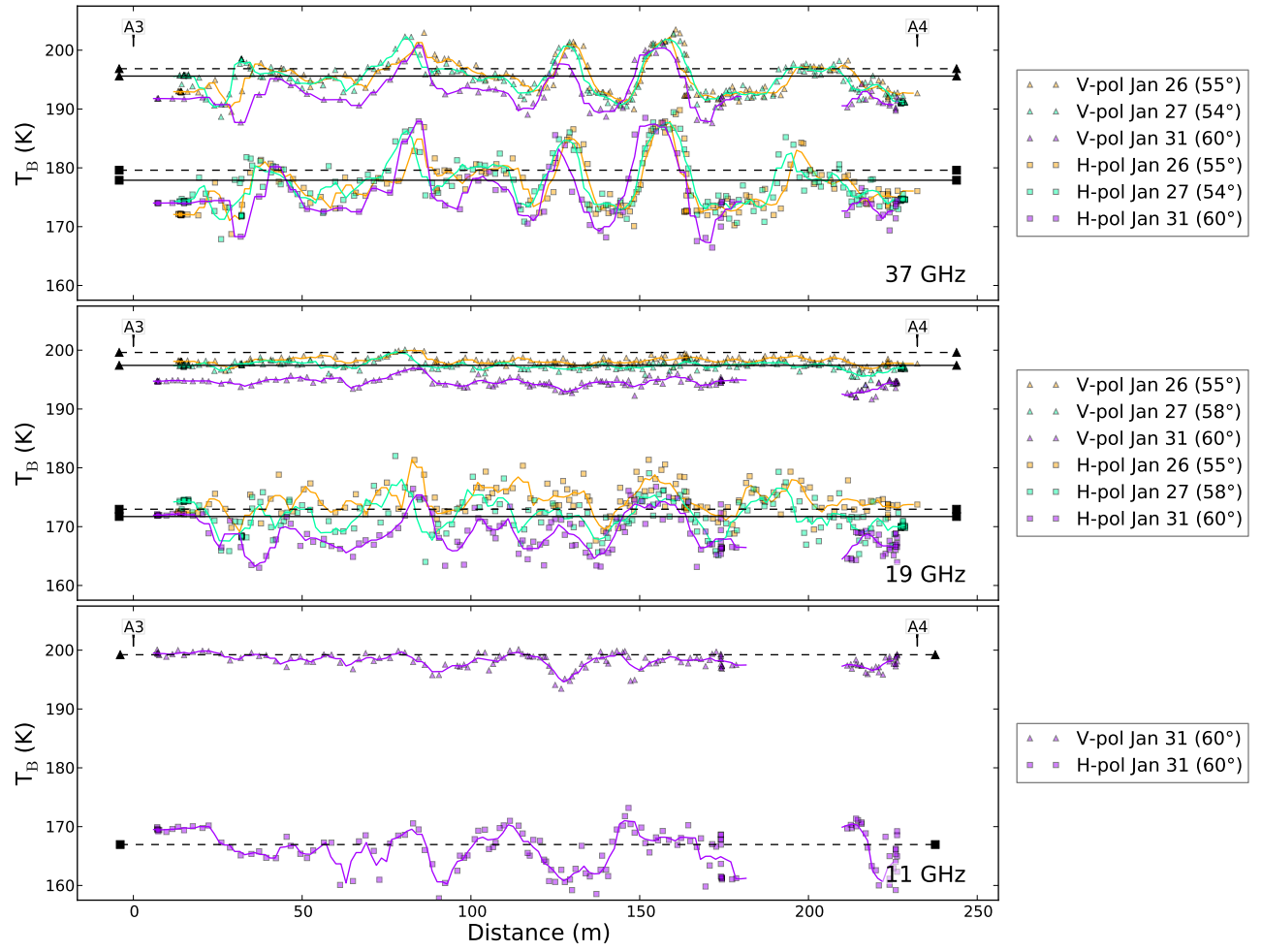

Figure 4. Brightness temperature measured along the A3-A4 transect on different dates (26, 27 and 31 January) for three frequencies (11, 19 and $37 \mathrm{GHz}$ ) and nearly constant incidence angle (its mean value along the transect is indicated in the legend). The symbols represent individual measurements at vertical polarization (triangles) and horizontal polarization (squares). The solid curves show the running average for a $6 \mathrm{~m}$ window. The horizontal black lines show the mean brightness temperature during the campaign of the pixel containing Dome $\mathrm{C}$ from SSM/I (solid line) and WindSat (dashed line).

simplification had a limited impact on the calculated brightness temperature since the e-folding penetration depth was about $4 \mathrm{~m}$ at $19 \mathrm{GHz}$ and $0.75 \mathrm{~m}$ at $37 \mathrm{GHz}$ (Surdyk, 2002; Brucker et al., 2011). The corresponding profiles of SSA, density and temperature are presented in Fig. 2 for both locations.

\section{Results}

The spatial variations of brightness temperature are analyzed using the two fine-resolution transects. To explain these variations, we present modeling simulations at two locations. The results are generalized using the longer coarse-resolution transects.

\subsection{Undulations along two fine-resolution transects}

The brightness temperatures measured along the A3-A4 transect (see Fig. 1) are shown in Fig. 4 as a function of the distance from A3 towards A4. The individual measurements (squares and triangles) and the smoothed curves (solid lines) show clear undulations. To confirm the reality of these undulations, we performed three passes on different days. Except an apparent shift of respectively +6 and $-6 \mathrm{~m}$ for the second and third passes, the undulations have similar characteristics for the three passes. The passes corrected from these GPS acquisition error are shown in Fig. 4. At $19 \mathrm{GHz}$ the brightness temperatures measured on 31 January are lower than the two other days. Even though the incidence angle was slightly higher and may partially explain this offset, the radiometer stability issue is another probable cause. The linear correlations between the passes are larger than 0.70 at $37 \mathrm{GHz}$ and 0.43 at $19 \mathrm{GHz}$, which is significant ( $p$ value $<0.01$ ). This confirms that the measurements are reproducible and the undulations are real.

The five undulations visible at $37 \mathrm{GHz}$ and vertical polarization along the $250 \mathrm{~m}$ of the transect are irregular and not strictly periodic. The local maxima are separated by about 44, 49, 30 and $41 \mathrm{~m}$ (average $41 \mathrm{~m}$ ). The location of the maxima is similar at all the frequencies and polarizations even though a sixth local maximum seems to emerge at horizontal polarization and $37 \mathrm{GHz}$. In contrast, the amplitude of the undulations largely depends on the frequency and polarization. It is higher at horizontal than vertical polarization (e.g., at $37 \mathrm{GHz}, 15$ and $10 \mathrm{~K}$ respectively) and seems to decrease with the frequency (e.g., at horizontal polarization, 15, 8 and $8 \mathrm{~K}$ at 37,19 and $11 \mathrm{GHz}$ ). The standard deviation for every configuration is reported in Table 1 and shows the same 


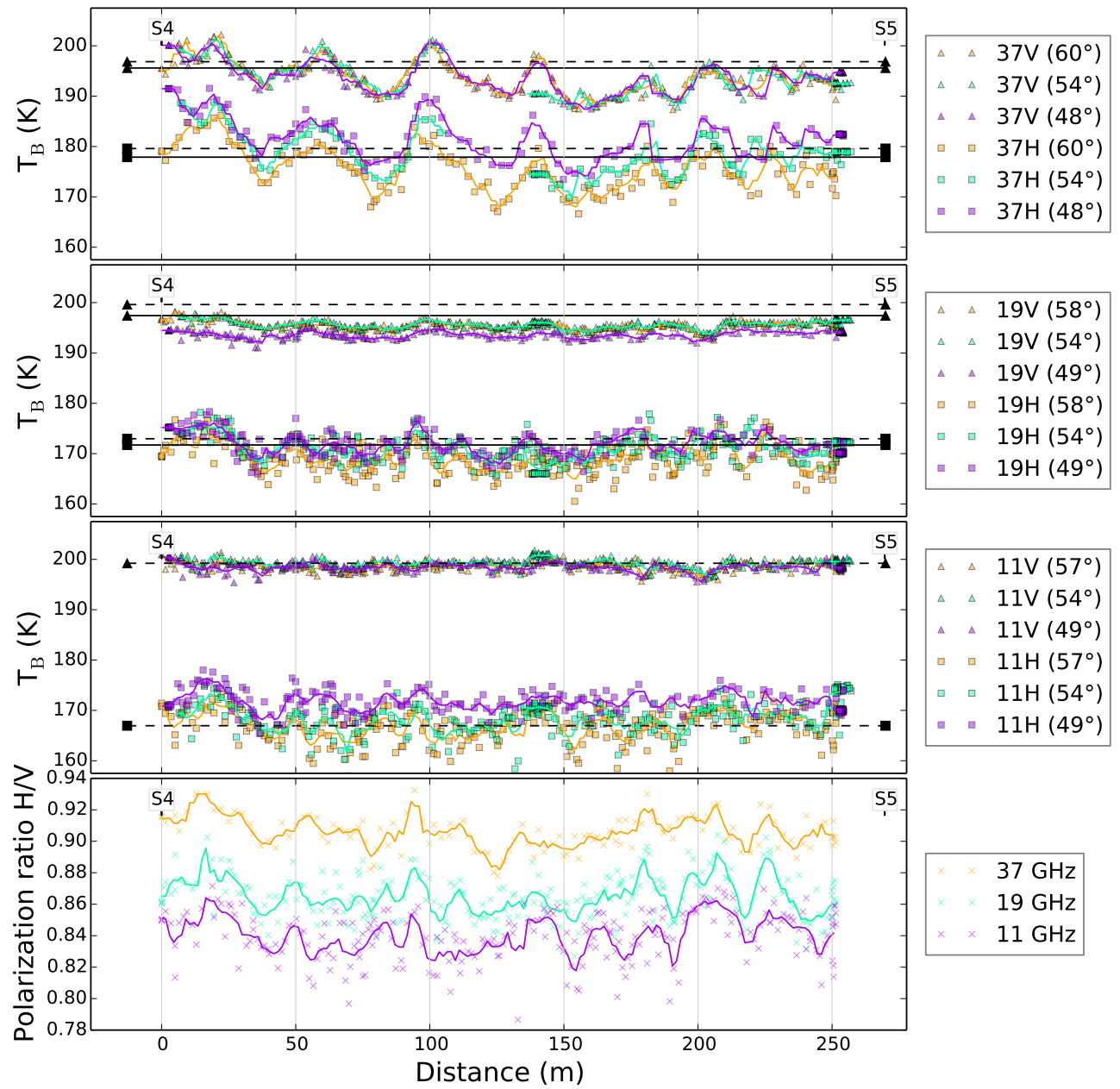

Figure 5. Brightness temperature (three top plots) and polarization ratio (bottom plot) measured along the S4-S5 transect at three frequencies $(11,19$ and $37 \mathrm{GHz})$ and for various incidence angles. The symbols represent individual measurements at vertical polarization (triangles), horizontal polarization (squares) and polarization ratio (cross). The curves show the running average with a $12 \mathrm{~m}$ window. The horizontal black lines show the mean brightness temperature during the campaign of the pixel containing Dome C from SSM/I (solid line) and WindSat (dashed line).

behavior: a decrease from high to low frequencies and from horizontal to vertical polarizations.

Figure 5 shows the brightness temperatures along the second fine-resolution transect, S4-S5. The different passes were acquired with different incidence angles one after another within about an hour. The general characteristics are similar to those of A3-A4. Seven local maximum, separated by a distance of $36 \mathrm{~m}$ on average, were found along the S4S5 transect. The amplitude of the undulations shows the same dependence on the polarization and frequency as found in the previous transect. The incidence angle influences the overall level of the brightness temperatures at horizontal polarization, and at vertical polarization at $19 \mathrm{GHz}$ only. In contrast, the different passes at $37 \mathrm{GHz}$ and vertical polarization are similar, which confirms the good reproducibility of the measurements.
The polarization ratio (PR) defined by $\mathrm{PR}=T_{B, h} / T_{B, v}$ is often used to characterize surface and interface reflections (Mätzler and Wegmüller, 1987; Shuman et al., 1993; Champollion et al., 2013). It is shown in Fig. 5 for the S4-S5 transect at the three frequencies. The undulations are visible for the PR because of the larger amplitude of the undulations at horizontal than at vertical polarization. As a consequence, the PR variations are positively correlated with brightness temperature variations. The most remarkable point is that the amplitude of PR is similar for the three frequencies while the amplitude is dependent on the frequency in the case of the brightness temperature. This indicates that the surface reflection is responsible for these variations (Shuman et al., 1993; Champollion et al., 2013). However, the large variation in the brightness temperature at V-polarization and at the Brewster angle - which is relatively insensitive to surface reflection - indicates that volume scattering was spatially variable as 
Table 1. Mean and standard deviation (in parentheses) of the brightness temperatures for the A3-A4 (at different dates) and S4-S5 (at difference incidence angles) transects; mean brightness temperatures measured by SSM/I and WindSat during the field campaign and corrected for the upwelling atmospheric contribution and the transmission through the atmosphere.

\begin{tabular}{lrrrrrr}
\hline Transect/passes & \multicolumn{2}{c}{$37 \mathrm{GHz}$} & \multicolumn{2}{c}{$19 \mathrm{GHz}$} & \multicolumn{2}{c}{$11 \mathrm{GHz}$} \\
& V-pol & H-pol & V-pol & H-pol & V-pol & H-pol \\
\hline Transect A3-A4 & & & & & & \\
25 Jan & $195.0(3.1)$ & $176.7(4.7)$ & $198.1(0.6)$ & $174.2(2.6)$ & n/a & n/a \\
26 Jan & $194.8(3.0)$ & $176.7(4.0)$ & $197.3(0.8)$ & $171.7(3.0)$ & n/a & n/a \\
31 Jan & $192.6(3.1)$ & $175.1(5.0)$ & $194.4(0.9)$ & $168.7(3.2)$ & $198.1(1.3)$ & $166.0(3.7)$ \\
& & & & & & \\
Transect S4-S5 & & & & & & \\
$60^{\circ}$ & $193.5(3.2)$ & $175.3(4.2)$ & $195.4(0.9)$ & $169.0(2.9)$ & $198.7(1.0)$ & $166.9(3.3)$ \\
$54^{\circ}$ & $193.3(3.1)$ & $178.7(4.0)$ & $195.8(0.8)$ & $170.9(2.7)$ & $199.4(1.0)$ & $169.4(3.5)$ \\
$48^{\circ}$ & $194.3(3.2)$ & $182.2(4.2)$ & $193.7(0.8)$ & $171.8(2.4)$ & $198.5(0.9)$ & $171.6(2.2)$ \\
$42^{\circ}$ & $193.2(2.8)$ & $182.5(3.2)$ & $192.4(0.7)$ & $175.6(1.7)$ & $197.2(0.9)$ & $174.0(1.7)$ \\
& & & & & & \\
SSM/I & 195.6 & 177.9 & 197.4 & 171.7 & $\mathrm{n} / \mathrm{a}$ & $\mathrm{n} / \mathrm{a}$ \\
WindSat & 196.9 & 179.6 & 199.6 & 173.0 & 199.2 & 167.0 \\
\hline
\end{tabular}

well. Hence, we conclude that the variations observed in the brightness temperatures and PR are caused by two different electromagnetic mechanisms.

The next Sect. 3.2 seeks the origin of these mechanisms, and the Sect. 3.3 investigates how these results apply at longer length scales.

\subsection{Relationship between brightness temperature and snow properties}

In order to determine the snow properties responsible for the brightness temperature variations, we used the measurements collected at SP1 and SP2 (Fig. 2) to run the DMRT-ML model. We first analyze the radiometric measurements and, second, present the modeling results.

Figure 6 shows the measurements as a function of incidence angle at SP1 and SP2 and at 19 and $37 \mathrm{GHz}$ as symbols. These measurements present the same characteristic variations in terms of amplitude, frequency and polarization as for the transects A3-A4 and S4-S5. The angular dependences have a typical shape (e.g., Tsang and Kong, 2001; Dupont et al., 2014): the vertical polarization reaches a maximum between 50 and $60^{\circ}$ corresponding to the Brewster angle, and it is larger than the horizontal polarization. The horizontal polarization decreases with the incidence angle except for large angles for SP2, which could result from the heterogeneity of the surface and the variations of viewed area as a function of the incidence angle. Visually, the surface at SP2 was indeed more chaotic than at SP1.

The results of the DMRT-ML simulations are shown in Fig. 6 as solid and dashed curves for the vertical and horizontal polarizations respectively. These simulations were run with a value of $\phi=2.3$, a value obtained by manual adjustment to get agreement of the mean level between the observations and modeling results considering both frequencies,

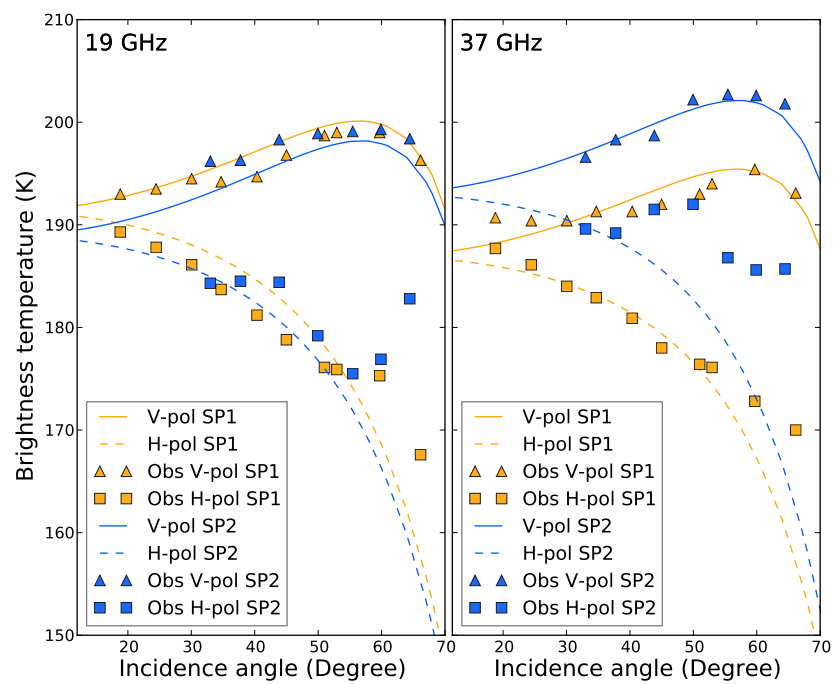

Figure 6. Measured and modeled brightness temperature as a function of the incidence angle for two locations (SP1 in orange and SP2 in blue), at horizontal (dashed curve and squares) and vertical (solid curve and triangles) polarizations, and at $19 \mathrm{GHz}$ (left) and $37 \mathrm{GHz}$ (right) frequencies.

both locations, and the vertical polarization. Increasing $\phi$ by 0.1 results in a general decrease of $1.5-2.3 \mathrm{~K}$ depending on the angle and location. It means that the optimization of the $\phi$ factor is able to absorb any possible constant error in the calibration of the radiometers, POSSSUM, density cutter, temperature, etc. However it could not modify the dependencies predicted by the model to the frequency, polarization and angle nor the differences between the two locations shown in Fig. 6. These dependencies and differences can thus be safely interpreted. 


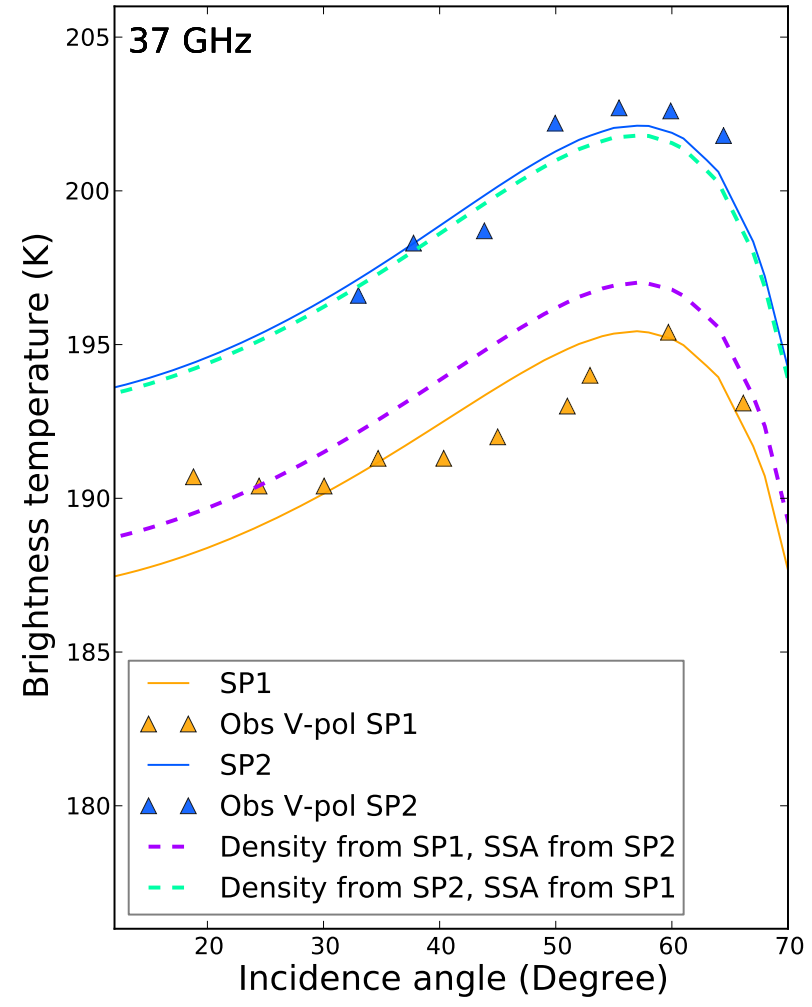

Figure 7. Measured and modeled brightness temperature as a function of the incidence angle for two locations at $37 \mathrm{GHz}$ and vertical polarization. Observations and simulations (solid lines) in Fig. 6 are repeated using the same symbols. In addition, simulations with mixed profiles are shown in purple (density from SP1 and SSA from SP2) and cyan (density from SP2 and SSA from SP2).

Table 2. Root mean square error between the modeling results and radiometric measurements at SP1 and SP2.

\begin{tabular}{lccc}
\hline $\begin{array}{l}\text { Frequency } \\
(\mathrm{GHz})\end{array}$ & Polarization & $\begin{array}{c}\text { RMSE at SP1 (K) } \\
n=10\end{array}$ & $\begin{array}{c}\text { RMSE at SP2 }(\mathrm{K}) \\
n=7\end{array}$ \\
\hline 19 & & 0.9 & 2.5 \\
19 & $\mathrm{~V}$ & 4.5 & 10.8 \\
37 & $\mathrm{H}$ & 1.5 & 1.2 \\
37 & $\mathrm{~V}$ & 5.2 & 11.2 \\
\hline
\end{tabular}

The error is quantified using the root mean square (rms) difference between the observations and modeled brightness temperatures over the $n=10$ observations for SP1 or $n=7$ for SP2. The rms errors reported in Table 2 show that the agreement is, in general, better by a factor of 2 for SP1 than SP2, and better by a factor of around 5 for the vertical than the horizontal polarization. However, the error is relatively independent of the frequency, which indicates that the vertical gradient of snow grain size and density is well captured by the measurements (Brucker et al., 2010).

The model reproduces the large difference between SP1 and $\mathrm{SP} 2$ at $37 \mathrm{GHz}$ and vertical polarization with an accu- racy sufficient to investigate the physical cause of the undulations observed on the transects. The temperature profile could not be responsible for the difference as it was identical in both simulations. To determine the respective influence of the grain size and density profiles, we ran two other simulations using the density profile of SP1 with the SSA profile of SP2, and vice versa. Figure 7 shows the results at $37 \mathrm{GHz}$ and vertical polarization compared to the original simulations and the observations. It clearly demonstrates that the exchange of the SSA profiles has a limited impact on the brightness temperature $(+1.6 \mathrm{~K}$ from orange to purple, and $-0.3 \mathrm{~K}$ from blue to cyan), whereas swapping the density profiles causes large variations $(+6.5 \mathrm{~K}$ from orange to cyan, and $-5.3 \mathrm{~K}$ from blue to purple) with direction and amplitude in agreement with the observations. It means that the density is the main factor explaining the difference in brightness temperature between the two sites. Another simulation where only the upper meter of the density profiles was swapped shows very similar results, indicating that the feature responsible for the differences was close to the surface. Density at SP1 and SP2 differs in the upper part of the snowpack: 390 and $410 \mathrm{~kg} \mathrm{~m}^{-3}$ respectively, on average in the first meter. According to electromagnetic theories (DMRT, Tsang and Kong, 2001, and an improved born approximation, Mätzler, 1998), a larger density leads to larger absorption and to weaker scattering in snow when the density is in the range of $250-500 \mathrm{~kg} \mathrm{~m}^{-3}$ (Fig. 7; Picard et al., 2013). Both effects combined decrease the single scattering albedo and increase the brightness temperature.

The increase observed at vertical polarization between SP1 and SP2 is also visible at horizontal polarization. At $37 \mathrm{GHz}$, the brightness temperature increase observed between SP1 and SP2 is larger at horizontal than vertical polarization so that the polarization ratio increases from about 0.89 to 0.92 at $55^{\circ}$, that is, in the range observed along the transect (Fig. 5). In contrast, at $19 \mathrm{GHz}$, the polarization ratio remains constant at 0.88 between SP1 and SP2. The model predicts a very small difference in the polarization ratio $(-0.1 \%)$ from SP1 to SP2, which tends to agree with the observations at $19 \mathrm{GHz}$ but disagrees with those at $37 \mathrm{GHz}$. This also disagrees with the results along the transects at all the frequencies.

The models' ability to predict the polarization ratio is generally good (Picard et al., 2013) but seems to be limited at incidence angles larger than $55^{\circ}$ and in the case of SP2 as shown in Fig. 6. In fact, the model largely underestimates the horizontal polarization at both frequencies and both locations. In the case of SP2 at $37 \mathrm{GHz}$, the underestimation is observed at every angle and is significant, almost $10 \mathrm{~K}$ at $55^{\circ}$. This problem is probably caused by the assumption of flat interfaces in the model. Ten centimeter-high sastrugi were observed everywhere, and the surface at SP2 was particularly chaotic. Little is known, in general, on the impact of sastrugi on the passive microwave signal. Several mechanisms may be significant according to Liang et al. (2009) and Chang and Tsang (2011) such as a direct effect related to the 


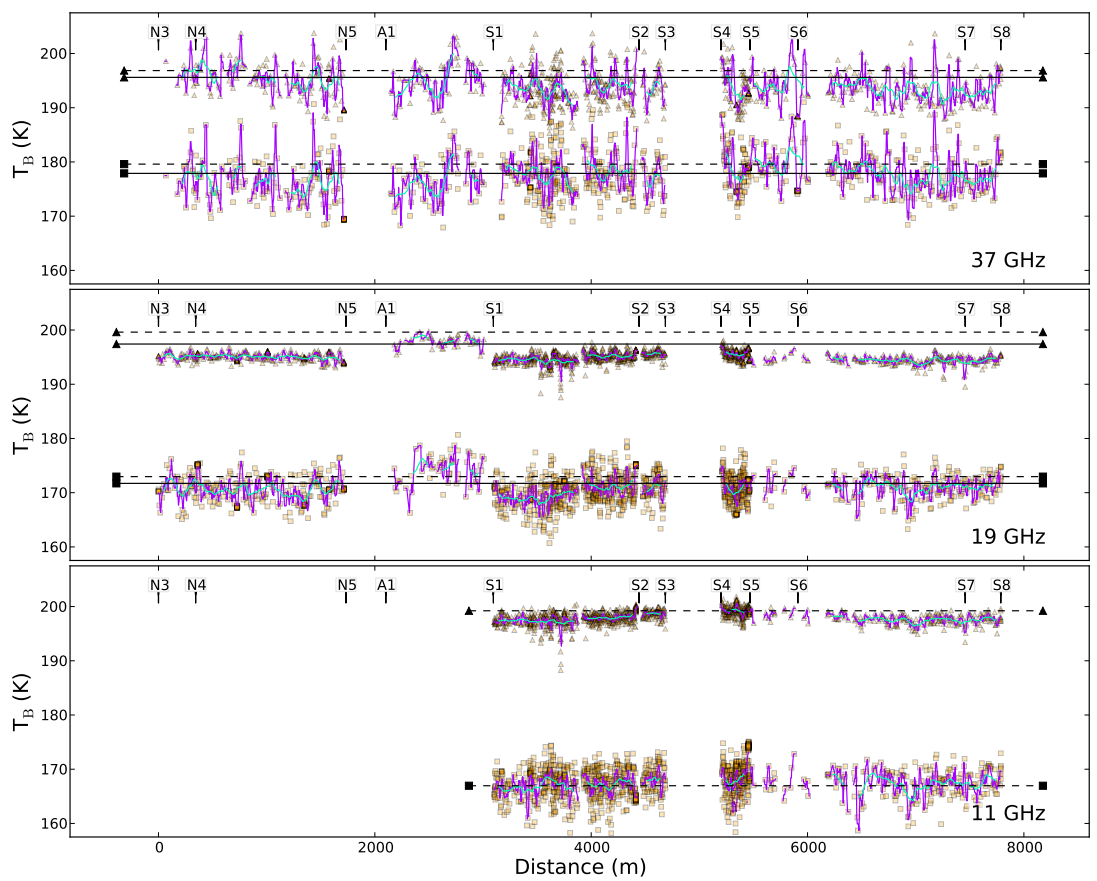

Figure 8. Brightness temperature measured along the N3-N4 (25 January), A1-S1 (26 January) and S1-S8 (31 January) transects for three frequencies $(11,19$ and $37 \mathrm{GHz})$ and nearly constant incidence angles (52 and $57^{\circ}$ ). The symbols represent individual measurements at vertical polarization (triangles) and horizontal polarization (squares). The solid curves, violet and blue, show the running average with a box window of 20 and $200 \mathrm{~m}$ respectively. The horizontal black lines show the mean brightness temperature during the campaign for the pixel including Dome C from SSM/I (solid line) and WindSat (dashed line).

local slope of the surface and total reflections of emerging radiation, or an indirect effect involving the internal structure of the snowpack (Liang et al., 2009). These mechanisms would be more efficient at grazing angles, which corresponds with the discrepancy in Fig. 6.

Except at high incidence angles for horizontal polarization, the modeling results are accurate enough to conclude that the snow density in the upper meter of the snowpack is the main driver of the variations of brightness temperature between SP1 and SP2.

\subsection{Long transects and SSM/I observations}

A series of transects totaling nearly $8 \mathrm{~km}$ are shown in Fig. 8 covering most of the available transects N3-N4, A1-S1, and S1-S8 (see Fig. 1). The abscissa is the distance along the trajectory starting from the northernmost point N3. The curves show the running average with a $20 \mathrm{~m}$ (purple) and $200 \mathrm{~m}$ (blue) box window.

The undulations could not be identified individually along these transects as it was the case for the A3-A4 and S4-S5 transects. This is probably because of the coarser resolution. According to the sampling theorem (Shannon, 1949), undulations should be visible since the spatial resolution $(\approx 7 \mathrm{~m}$ at $19 \mathrm{GHz}$ and $\approx 14 \mathrm{~m}$ at $37 \mathrm{GHz}$ ) was less than half of the typical period of the undulations $(\approx 40 \mathrm{~m})$. The computation of the power spectra using irregular fast Fourier transform
(Greengard and Lee, 2004, results not shown) shows peaks in the range of 30-60 m, but they are not significant. On the other hand, the distance between the undulations observed in Sect. 3.1 is not constant, and the twice coarser resolution at $37 \mathrm{GHz}$ (the most sensitive frequency) prevents detection of undulations.

Although the undulations are not resolved, the signal has some statistical characteristics in common with the fineresolution transects analyzed in Sect. 3.1: the amplitude of the variations is on the same order (see standard deviations in Table 1), and its dependence on the frequency and polarization is very similar - that is, the amplitude is larger at $37 \mathrm{GHz}$ than at the lower frequencies, and it is larger at horizontal than at vertical polarization. In addition, most of the variations are concentrated at length scales less than about $100 \mathrm{~m}$. This suggests that the variations observed along the two transects, A3-A4 and S4-S5, are not isolated cases but are representative of the area. Given the large amplitude of these variations, it is important to consider them to understand the brightness temperature observed by satellites.

The $200 \mathrm{~m}$ running average (blue curve in Fig. 8) shows variations of $5 \mathrm{~K}$ (peak to trough) at $37 \mathrm{GHz}$ and vertical polarization, and $3 \mathrm{~K}$ at $19 \mathrm{GHz}$ and horizontal polarization, for instance. Weak variations at kilometer scales may also be present, but the stability problem of the radiometers during the experiment prevents conclusion. For instance, the data 


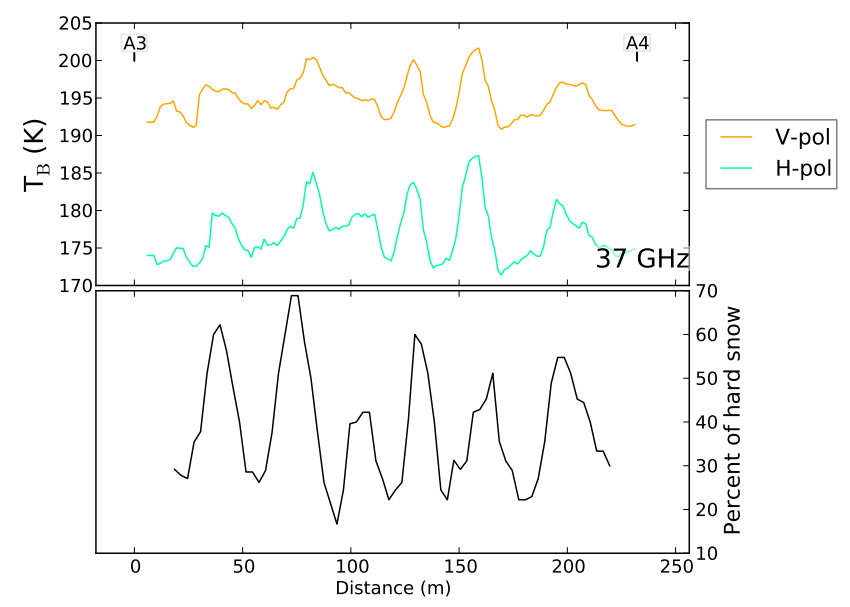

Figure 9. Hardness tested manually along the A3-A4 transect as a function of distance. The penetration in the top $30 \mathrm{~cm}$ of the snowpack was tested using a stick with a $10 \mathrm{~mm}$ diameter. The percent of hard snow was calculated by accounting for all these tests in a window ( $30 \mathrm{~m}$ cross-track by $12 \mathrm{~m}$ along track) moving along the transect.

acquired at $19 \mathrm{GHz}$ on 26 January along A3-A4 (Fig. 4 and between $\mathrm{A} 1$ and $\mathrm{S} 1$ in Fig. 8) are systematically greater than the data acquired on 25 and 31 January by about $2.5 \mathrm{~K}$. Nevertheless, even considering the uncertainty due to the experimental conditions, we can conclude that the variability decreases with increasing length scales from decameters to kilometers.

The brightness temperatures acquired by satellite, SSM/I (solid line) and WindSat (dashed line), are shown in Figs. 4, 5 and 8 . The data correspond to the pixel including Concordia and are the average over the duration of the campaign. The small differences obtained between the two satellites may be due to differences in the sensors (frequency, incidence angle), calibration, and/or error due to the geo-spatial projection. Nevertheless, the agreement between the satellite observations and the ground-based radiometer data is close, on average, despite the large difference of spatial resolution and possible uncertainty in the atmospheric correction. It suggests that the area that we investigated around Concordia was representative of the whole pixel.

\section{Discussion}

The variations of brightness temperature along the two fineresolution transects are significant at $37 \mathrm{GHz}$ (about $10 \mathrm{~K}$ ) and dominated by undulations separated by about $40 \mathrm{~m}$. It is evident in the field that the maximum brightness temperature is almost systematically found in areas of very hard snow. Indeed, the tip of a pencil (cohesiveness index 4; Fierz et al., 2009) could not penetrate the snow, and the tracks of our vehicle left only traces of the spikes although they entirely sank, about $5 \mathrm{~cm}$ deep, everywhere else. Areas of hard snow were present everywhere along the $8 \mathrm{~km}$ of the transects, and we noticed a strong correlation with the maximum brightness temperature. Even though the undulations are not directly visible in the microwave data for the coarse-resolution transects (Fig. 8), there is no doubt that the maxima were related to snow hardness.

The snow property measurements collected at SP1 ("normal area", low brightness temperature) and SP2 ("hard snow area", high brightness temperature) and the radiative transfer model results (Sect. 3.2) show that the difference in brightness temperature is mainly explained by the density in the upper part of the snowpack. The density is indeed higher at SP2, particularly in the top $30 \mathrm{~cm}$ (on average $445 \mathrm{~kg} \mathrm{~m}^{-3}$ at SP2 and $375 \mathrm{~kg} \mathrm{~m}^{-3}$ at SP1), which agree with the greater hardness of the snow (even though such a difference is moderate with respect to the vertical variability, and hardness and density are not strictly related in general). The density profile at SP2 suggests that the vertical extent of the hard snow layer is no more than $50 \mathrm{~cm}$. This was also consistent with our experience in drilling SP2. The horizontal extent was not precisely measured at SP2, but we estimated the emerging part to be about $10 \mathrm{~m}$ wide. The measurements for the transect near SP2 (not shown) and for the A3-A4 and S4-S5 transects (Figs. 4 and 5) suggest a larger extent, about $20 \mathrm{~m}$, since the brightness temperature undulations are separated by about $40 \mathrm{~m}$ and the shape of the undulation is nearly symmetric above and below the mean. It is likely that only a fraction of the hard snow emerges at the surface, and the feature is indeed $20 \mathrm{~m}$ wide. These results imply that nearly half of the surface area was hard snow.

Additional measurements along the A3-A4 transect were conducted during the 2012-2013 summer campaign to check this hypothesis. The penetration of a stick ( $10 \mathrm{~mm}$ diameter) into the snowpack was tested every $1 \mathrm{~m}$ by six people walking in parallel, at a distance of about $5 \mathrm{~m}$ from each other. Two clearly distinct types of snow were found: areas with no hard layer (i.e., the stick penetrated easily up to $30 \mathrm{~cm}$ depth) and areas with at least one hard layer between 0 and $30 \mathrm{~cm}$ (i.e., the stick was blocked before reaching a depth of $30 \mathrm{~cm}$ (hardness below was not tested)). A total of $39 \%$ of the tests indicate hard snow. To refine this, we calculated the percent of hard snow as a function of the distance along the transect with a moving window ( $12 \mathrm{~m}$ along the transect by $25 \mathrm{~m}$ perpendicular to the transect). The result is shown in Fig. 9 along with the brightness temperature at $37 \mathrm{GHz}$ averaged for the three dates (see Fig. 4). The correlation between the microwave signal and the percent of hard snow is remarkable, accounting for possible changes over 1 year, GPS geolocalization errors and the subjectiveness of this simple test.

During the austral summer of 2006-2007, an exceptional situation was noticed. Many areas with emerging hard snow were clearly visible in the region near S4-S5. We studied one of these areas in detail (unpublished data): the contour was identified using a stick and materialized in Fig. 10a with a red line. The shape was roughly circular with a diameter 


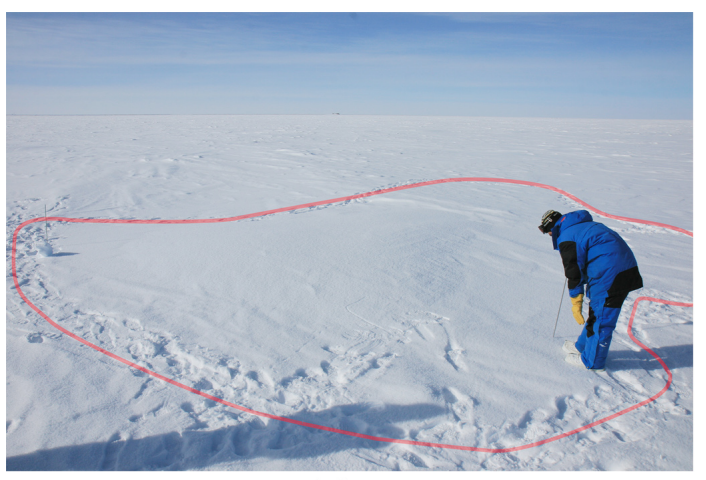

(a)

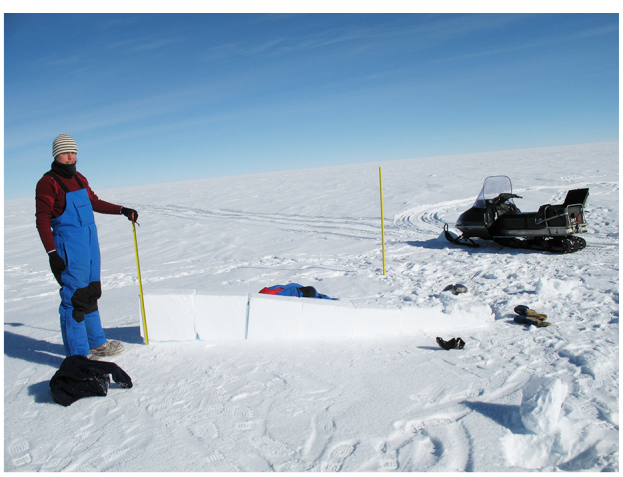

(b)

Figure 10. (a) Contour of a "whale back" and (b) longitudinal slice extracted from the same "whale back" in 2006-2007.

of $10-15 \mathrm{~m}$. The thickness was about $50 \mathrm{~cm}$ at the center and regularly decreased towards the borders (Fig. 10b). Because of its shape, size and emergence above the mean surface, it was called "whale back". The density was above $500 \mathrm{~kg} \mathrm{~m}^{-3}$, and the hardness was very high (cohesiveness index 5), which was much higher than the density measured at SP2 in 2012 in the first meter. On the other hand, the SSA was the same as in "normal snow" areas $\left(\approx 25 \mathrm{~m}^{2} \mathrm{~kg}^{-1}\right)$. We cannot ascertain whether this particularly regular feature was what caused the variations of brightness temperature everywhere. In 2012, there was less evidence of such emerging "whale backs", and the hard snow area around SP2 seemed irregular. Nevertheless, the general characteristics were similar.

The formation of the 2012 features was very likely driven by the wind and involved the compaction of small fine grains leading to a highly cohesive wind-packed layer. According to Kobayashi and Ishida (1979), these features could be transverse waves (also known as barchan dunes). In fact, the wind speed at Dome C is rarely above the theoretical threshold (15 $\mathrm{m} \mathrm{s}^{-1}$; Kobayashi and Ishida, 1979) to form longitudinal dunes. In addition, the contour drawn in 2006 (Fig. 10) was not elongated as in the case of longitudinal dunes. Moreover, in 2012, there was no sign of particular alignments and the brightness temperatures along the A3-A4 and S4-S5 transects show similar variations despite the different orientation with respect to the prevailing wind direction. Specific detailed observations of these features are needed in the future to understand their origin. Another key question is whether the areal proportion of these features can significantly change over time. With a difference of about $10 \mathrm{~K}$ at $37 \mathrm{GHz}$ between hard and normal snow areas, if the proportion changed by say $10 \%$ over time, the brightness temperature would change by about $1 \mathrm{~K}$.

\section{Conclusions}

Using ground-based radiometers towed by a vehicle in the area around Dome $\mathrm{C}$ in Antarctica, we investigated the spatial variability of the brightness temperatures at 11, 19 and $37 \mathrm{GHz}$ for length scales from meters to kilometers. These observations revealed that variations are significant at the meter/decameter scales, especially for the highest frequency. The analysis and the simulations conducted with an electromagnetic model indicate that these variations are mainly caused by the alternation of dense/hard and light/loose snow areas with a quasi-period of $30-50 \mathrm{~m}$. The hard snow areas, representing approximately $40 \%$ of the investigated area in summers 2011-2012 and 2012-2013, seem to be features formed by the wind, that is, dunes or "whale backs", despite the moderate wind speeds encountered at Dome C.

The study also shows that, for the hectometer to kilometer scales, the variations are much smaller. The average of the ground-based brightness temperature is close to the SSM/I and WindSat satellite observations meaning that the investigated area was representative of the pixel of the satellites including Dome C. An important consequence is that spaceborne passive microwave sensors cannot spatially resolve these wind-formed features, but they are very sensitive to the areal proportion of these features. It means that changes in emissivity, like those observed by Lacroix et al. (2009) in the Vostok area, might be solely due to a change in the proportion of these features without significant changes in the properties of the different areas.

Acknowledgements. This work would not have been possible without the logistical and financial support of the IPEV French polar institute programmes BIPOL and CALVA. The French Agence Nationale de la Recherche ANR VANISH (program ANR-07VULN-013 VANISH), NSERC-Canada and Sherbrooke University also provided financial support. The manuscript was written, in part, during a visit to Sherbrooke University supported by the grant CMIRA 2012 ExploraPro, Region Rhône-Alpes. Measurements in 2012 were conducted in the framework of the ANR MONISNOW 
program. We acknowledge the Naval Research Laboratory, Naval Center for Space Technology, Washington, DC 20375 USA, which provided the WindSat data through Computational Physics, Inc. (http://www.cpi.com/projects/ws.html). We thank T. Scambos, C. Mätzler and R. Kelly for reviewing this paper.

Edited by: R. Kelly

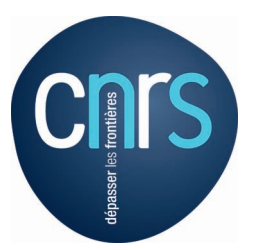

The publication of this article is financed by CNRS-INSU.

\section{References}

Abdalati, W. and Steffen, K.: Passive microwave-derived snow melt regions on the Greenland ice sheet, Geophys. Res. Lett., 22, 787790, doi:10.1029/95GL00433, 1995.

Anschütz, H., Eisen, O., Rack, W., and Scheinert, M.: Periodic surface features in coastal East Antarctica, Geophys. Res. Lett., 33, L22501, doi:10.1029/2006GL027871, 2006.

Arnaud, L., Picard, G., Champollion, N., Domine, F., Gallet, J., Lefebvre, E., Fily, M., and Barnola, J.: Measurement of vertical profiles of snow specific surface area with a $1 \mathrm{~cm}$ resolution using infrared reflectance: instrument description and validation, J. Glaciol., 57, 17-29, doi:10.3189/002214311795306664, 2011.

Arthern, R. J., Winebrenner, D. P., and Vaughan, D. G.: Antarctic snow accumulation mapped using polarization of $4.3-\mathrm{cm}$ wavelength microwave emission, J. Geophys. Res., 111, D06107, doi:10.1029/2004JD005667, 2006.

Brucker, L., Picard, G., and Fily, M.: Snow grain size profiles deduced from microwave snow emissivities in Antarctica, J. Glaciol., 56, 514-526, doi:10.3189/002214310792447806, 2010

Brucker, L., Picard, G., Arnaud, L., Barnola, J., Schneebeli, M., Brunjail, H., Lefebvre, E., and Fily, M.: Modeling time series of microwave brightness temperature at Dome C, Antarctica, using vertically resolved snow temperature and microstructure measurements, J. Glaciol., 57, 171-182, 2011.

Champollion, N., Picard, G., Arnaud, L., Lefebvre, E., and Fily, M.: Hoar crystal development and disappearance at Dome C, Antarctica: observation by near-infrared photography and passive microwave satellite, The Cryosphere, 7, 1247-1262, doi:10.5194/tc-7-1247-2013, 2013.

Chang, W. and Tsang, L.: Conical electromagnetic waves diffraction from sastrugi type surfaces of layered snow dunes on Greenland ice sheets in passive microwave remote sensing, in Proc. IGARSS, 122-125, 2011.

Colton, M. C. and Poe, G. A.: Intersensor calibration of DMSP SSM/I's: F-8 to F-14, 1987-1997, IEEE T. Geosci. Remote, 37, 418-439, doi:10.1109/36.739079, 1999.

Courville, Z. R., Albert, M. R., Fahnestock, M. A., Cathles IV, L. M., and Shuman, C. A.: Impacts of an accumulation hiatus on the physical properties of firn at a low-accumulation polar site, J. Geophys. Res., 112, F02030, doi:10.1029/2005JF000429, 2007.
Das, I., Bell, R. E., Scambos, T. A., Wolovick, M., Creyts, T. T., Studinger, M., Frearson, N., Nicolas, J. P., Lenaerts, J. T. M., and van den Broeke, M. R.: Influence of persistent wind scour on the surface mass balance of Antarctica, Nat. Geosci., 6, 367-371, doi:10.1038/ngeo1766, 2013.

Dierking, W., Linow, S., and Rack, W.: Toward a robust retrieval of snow accumulation over the Antarctic ice sheet using satellite radar, J. Geophys. Res., 117, D09110, doi:10.1029/2011JD017227, 2012.

Dupont, F., Picard, G., Royer, A., Fily, M., Roy, A., and Champollion, N.: Modeling the microwave emission of ice; Applications to the Cap Prud'Homme Blue Ice Area in Antarctica and to the Barnes Ice Cap superimposed ice in Arctic, IEEE T. Geosci. Remote, 52, 6639-6651, doi:10.1109/TGRS.2014.2299829, 2014.

Fahnestock, M. A., Scambos, T. A., Shuman, C. A., Arthern, R. J., Winebrenner, D. P., and Kwok, R.: Snow megadune fields on the East Antarctic Plateau: extreme atmosphere-ice interaction, Geophys. Res. Lett., 27, 3719-3722, doi:10.1029/1999GL011248, 2000.

Fierz, C., Armstrong, R. L., Durand, Y., Etchevers, P., Greene, E., McClung, D. M., Nishimura, K., Satyawali, P. K., and Sokratov, S. A.: The international classification for seasonal snow on the ground, UNESCO/IHP, 2009.

Frezzotti, M., Gandolfi, S., La Marca, F., and Urbini, S.: Snow dunes and glazed surfaces in Antarctica: new field and remotesensing data, Ann. Glaciol., 34, 81-88, 2002a.

Frezzotti, M., Gandolfi, S., and Urbini, S.: Snow megadunes in Antarctica: sedimentary structure and genesis, J. Geophys. Res., 107, 4344, doi:10.1029/2001JD000673, 2002b.

Furukawa, T., Kamiyama, K., and Station, M. H.: Snow surface features along the traverse route from the coast to Dome Fuji and Queen Maud Land and Antarctica, in: Proc NIPR Symp. Polar Meteorol. Glaciol., vol. 10, 13-24, 1996.

Gaiser, P., St. Germain, K., Twarog, E., Poe, G., Purdy, W., Richardson, D., Grossman, W., Jones, W., Spencer, D., Golba, G., Cleveland, J., Choy, L., Bevilacqua, R., and Chang, P.: The WindSat spaceborne polarimetric microwave radiometer: sensor description and early orbit performance, IEEE T. Geosci. Remote, 42, 2347-2361, doi:10.1109/TGRS.2004.836867, 2004.

Gallet, J.-C., Domine, F., Zender, C. S., and Picard, G.: Measurement of the specific surface area of snow using infrared reflectance in an integrating sphere at 1310 and $1550 \mathrm{~nm}$, The Cryosphere, 3, 167-182, doi:10.5194/tc-3-167-2009, 2009.

Goodwin, I. D.: Snow accumulation and surface topography in the katabatic zone of Eastern Wilkes Land, Antarctica, Antarct. Sci., 2, 235-242, doi:10.1017/S0954102090000323, 1990.

Gow, A. J.: On the rates of growth of grains and crystals in south polar firn, J. Glaciol., 8, 241-252, 1969.

Greengard, L. and Lee, J.: Accelerating the nonuniform fast fourier transform, SIAM Rev., 46, 443-454, doi:10.1137/S003614450343200X, 2004.

Grenfell, T. C. and Warren, S. G.: Representation of a nonspherical ice particle by a collection of independent spheres for scattering and absorption of radiation, J. Geophys. Res., 104, $31697-$ 31710, doi:10.1029/1999JD900496, 1999.

Guedj, S., Karbou, F., Rabier, F., and Bouchard, A.: Toward a better modeling of surface emissivity to improve AMSU data assimilation over Antarctica, IEEE T. Geosci. Remote, 48, 1976-1985, doi:10.1109/TGRS.2009.2036254, 2010. 
Hyland, G. and Young, N.: Wind-induced directional anisotropy of microwave backscatter and its impact on imaging of the Antarctic continental snow cover, Int. Geosci. Remote Se., 4, 1988-1990, doi:10.1109/IGARSS.1998.703717, 1998.

Jezek, K. C.: Glaciological properties of the Antarctic ice sheet from RADARSAT-1 synthetic aperture radar imagery, Ann. Glaciol., 29, 286-290, doi:10.3189/172756499781820969, 1999.

Kerr, Y. H., Waldteufel, P., Wigneron, J.-P., Cabot, F., Boutin, J., Escorihuela, M.-J., Font, J., Reul, N., Gruhier, C., Juglea, S., Delwart, S., Drinkwater, M., Hahne, A., Martin-Neira, M., and Mecklenburg, S.: The SMOS mission: new tool for monitoring key elements ofthe global water cycle, P. IEEE, 98, 666-687, doi:10.1109/JPROC.2010.2043032, 2010.

Kerr, Y. H., Waldteufel, P., Richaume, P., Wigneron, J. P., Ferrazzoli, P., Mahmoodi, A., Al Bitar, A., Cabot, F., Gruhier, C., Juglea, S. E., Leroux, D., Mialon, A. and Delwart, S.: The SMOS soil moisture retrieval algorithm, IEEE T. Geosci. Remote, 50, 1384-1403, doi:10.1109/TGRS.2012.2184548, 2012.

Kobayashi, S. and Ishida, T.: Interaction between wind and snow surface, Bound.-Lay. Meteorol., 16, 35-47, doi:10.1007/BF02524396, 1979.

Koenig, L. S., Steig, E. J., Winebrenner, D. P., and Shuman, C. A.: A link between microwave extinction length, firn thermal diffusivity, and accumulation rate in West Antarctica, J. Geophys. Res., 112, F03018, doi:10.1029/2006JF000716, 2007.

Lacroix, P., Legresy, B., Remy, F., Blarel, F., Picard, G., and Brucker, L.: Rapid change of snow surface properties at Vostok, East Antarctica, revealed by altimetry and radiometry, Remote Sens. Environ., 113, 2633-2641, doi:10.1016/j.rse.2009.07.019, 2009.

Liang, D., Xu, P., Tsang, L., Gui, Z., and Chen, K.: Electromagnetic scattering by rough surfaces with large heights and slopes with applications to microwave remote sensing of rough surface over layered media, Pr. Electromagn. Res. S., 95, 199-218, doi:10.2528/PIER09071413, 2009.

Liebe, H. : MPM - an atmospheric millimeter-wave propagation model, Int. J. Infrared. Milli., 10, 631-650, doi:10.1007/BF01009565, 1989.

Long, D. G. and Drinkwater, M. R.: Azimuth variation in microwave scatterometer and radiometer data over Antarctica, IEEE T. Geosci. Remote, 38, 1857-1870, doi:10.1109/36.851769, 2000.

Macelloni, G., Brogioni, M., and Pampaloni, P.: An experimental campaign in Antarctica for the calibration of low-frequency space-borne radiometers, Int. Geosci. Remote Se., 3980-3983, doi:10.1109/IGARSS.2006.1021, 2006.

Macelloni, G., Brogioni, M., Pampaloni, P., and Cagnati, A.: Multifrequency microwave emission fromthe Dome-C area on the East Antarctic plateau: temporal and spatial variability, IEEE T. Geosci. Remote, 45, 2029-2039, doi:10.1109/TGRS.2007.890805, 2007.

Magand, O., Picard, G., Brucker, L., Fily, M., and Genthon, C.: Snow melting bias in microwave mapping of Antarctic snow accumulation, The Cryosphere, 2, 109-115, doi:10.5194/tc-2-1092008, 2008.

Maslanik, J. and Stroeve, J.: DMSP SSM/I-SSMIS Daily Polar Gridded Brightness Temperatures, Version 4, Boulder, Colorado USA: NASA DAAC at the National Snow and Ice Data Center, 2012.
Mätzler, C.: Improved Born approximation for scattering of radiation in a granular medium, J. Appl. Phys., 83, 6111-6117, 1998.

Mätzler, C. and Wegmüller, U.: Dielectric properties of freshwater ice at microwave frequencies, J. Phys. D. Appl. Phys., 20, 1623, doi:10.1088/0022-3727/20/12/013, 1987.

Narvekar, P. S., Heygster, G., Jackson, T. J., Bindlish, R., and Li, L.: Azimuthal variations in polarimetric microwave measurements observed over Dome C, Antarctica, in: Society of Photo-Optical Instrumentation Engineers (SPIE) Conference Series, vol. 6410 of Society of Photo-Optical Instrumentation Engineers (SPIE) Conference Series, doi:10.1117/12.693503, 2006.

Narvekar, P. S., Heygster, G., Jackson, T., Bindlish, R., Macelloni, G., and Notholt, J.: Passive polarimetric microwave signatures observed over Antarctica, IEEE T. Geosci. Remote, 48, 1059-1075, doi:10.1109/TGRS.2009.2032295, 2010.

Nolin, A., Fetterer, F., and Scambos, T.: Surface roughness characterizations of sea ice and ice sheets: case studies with MISR data, IEEE T. Geosci. Remote, 40, 1605-1615, doi:10.1109/TGRS.2002.801581, 2002.

Painter, T. H., Rittger, K., McKenzie, C., Slaughter, P., Davis, R. E., and Dozier, J.: Retrieval of subpixel snow covered area, grain size, and albedo from MODIS, Remote Sens. Environ., 113, 868879, doi:10.1016/j.rse.2009.01.001, 2009.

Picard, G., Brucker, L., Fily, M., Gallee, H., and Krinner, G.: Modeling timeseries of microwave brightness temperature in Antarctica, J. Glaciol., 55, 537-551, 2009.

Picard, G., Domine, F., Krinner, G., Arnaud, L., and Lefebvre, E.: Inhibition of the positive snow-albedo feedback by precipitation in interior Antarctica, Nature Climate Change, 2, 795-798, doi:10.1038/nclimate1590, 2012.

Picard, G., Brucker, L., Roy, A., Dupont, F., Fily, M., Royer, A., and Harlow, C.: Simulation of the microwave emission of multilayered snowpacks using the Dense Media Radiative transfer theory: the DMRT-ML model, Geosci. Model Dev., 6, 1061-1078, doi:10.5194/gmd-6-1061-2013, 2013.

Remy, F., Legresy, B., and Benveniste, J.: On the azimuthally anisotropy effects of polarization for altimetric measurements, IEEE T. Geosci. Remote, 44, 3289-3296, doi:10.1109/TGRS.2006.878444, 2006.

Roy, A., Picard, G., Royer, A., Montpetit, B., Dupont, F., Langlois, A., Derksen, C., and Champollion, N.: Brightness temperature simulations of the Canadian seasonal snowpack driven by measurements of the snow specific surface area, IEEE T. Geosci. Remote, 51, 4692-4704, doi:10.1109/TGRS.2012.2235842, 2013.

Scambos, T. A., Haran, T. M., Fahnestock, M. A., Painter, T. H., and Bohlander, J.: MODIS-based Mosaic of Antarctica (MOA) data sets: continent-wide surface morphology and snow grain size, Remote Sens. Environ., 111, 242-257, 2007.

Scambos, T. A., Frezzotti, M., Haran, T., Bohlander, J., Lenaerts, J., Van Den Broeke, M., Jezek, K., Long, D., Urbini, S., Farness, K., Neumann, T., Albert, M., and Winther, J.: Extent of lowaccumulation "wind glaze" areas on the East Antarctic plateau: implications for continental ice mass balance, J. Glaciol., 58, 633-647, doi:10.3189/2012JoG11J232, 2012.

Schneider, D. P. and Steig, E. J.: Spatial and temporal variability of Antarctic ice sheet microwave brightness temperatures, Geophys. Res. Lett., 29, 1964, doi:10.1029/2002GL015490, 2002. 
Schneider, D. P., Steig, E. J., and Comiso, J. C.: Recent climate variability in Antarctica from satellite-derived temperature data, J. Climate, 17, 1569-1583, 2004.

Shannon, C.: Communication in the presence of noise, P. IRE, 37, 10-21, doi:10.1109/JRPROC.1949.232969, 1949.

Shuman, C. A., Alley, R. B., and Anandakrishnan, S.: Characterization of a hoar-development episode using SSM/I brightness temperatures in the vicinity of the GISP2 site, Greenland, Ann. Glaciol., 17, 183-188, 1993.

Shuman, C. A., Alley, R. B., Anandakrishnan, S., and Stearns, C. R.: An empirical technique for estimating near-surface air temperature trends in central Greenland from SSM/I brightness temperatures, Remote Sens. Environ., 51, 245-252, 1995.

Surdyk, S.: Using microwave brightness temperature to detect short-term surface air temperature changes in Antarctica: an analytical approach, Remote Sens. Environ., 80, 256-271, 2002.
Torinesi, O., Fily, M., and Genthon, C.: Interannual variability and trend of the Antarctic summer melting period from 20 years of spaceborne microwave data, J. Climate, 16, 1047-1060, 2003.

Tsang, L. and Kong, J. A.: Scattering of Electromagnetic Waves, vol. 3, Advanced Topics, Wiley Interscience, New York, 2001.

van den Broeke, M., Konig-Langlo, G., Picard, G., Kuipers M. P., and Lenaerts, J.: Surface energy balance, melt and sublimation at Neumayer Station, East Antarctica, Antarct. Sci., 22, 87-96, doi:10.1017/S0954102009990538, 2009.

Vaughan, D. G., Bamber, J. L., Giovinetto, M., Russell, J., and Cooper, A. P. R.: Reassessment of net surface mass balance in Antarctica, J. Climate, 12, 933-946, 1999.

Zwally, H. J.: Microwave emissivity and accumulation rate of polar firn, J. Glaciol., 18, 195-214, 1977. 